\author{
A respeito da presença da emigração na \\ fotografia histórica galega.
}

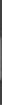

\author{
Manuel Sendón
}

Artigo recebido em: 07/11/2020

Artigo aprovado em: 20/12/2020 


\title{
A respeito da presença da emigração na fotografia histórica galega
}

\section{Concerning the Presence of Emigration in Galician Historical Photography}

\author{
Manuel Sendón*
}

Resumo: Nas últimas décadas proliferaram os projetos de recuperação de fotografia histórica, revalorizando um património cultural que ultrapassa o artístico, permitindo interrogar a nossa memória recente, as experiências quotidianas $e$ as utilizações sociais das fotografias. Este texto abordará tudo isto a partir do trabalho do Centro Galego de Estudos Fotográficos de Vigo na recuperação da fotografia popular, a respeito de uma experiência fundamental no contexto galego do século passado: a da emigração.

Palavras-chave: Fotografia popular. Retrato fotográfico. Galiza. Emigração. Memória.

\begin{abstract}
In recent decades, projects for the recovery of historical photography have proliferated; revaluing a cultural heritage that goes beyond the artistic, allowing us to interrogate our recent memory, daily experiences and the social uses of photographs. This paper will address all of this based on the work of the Galician Center for Photographic Studies in Vigo in the recovery of popular photography, in relation to a fundamental experience in the Galician context of the last century: the emigration.
\end{abstract}

Keywords: Popular photography. Photographic portrait. Galicia. Emigration. Memory.

* Fotógrafo, comisario y docente. Facultad de Bellas Artes de Vigo, Centro Galego de Estudos Fotográficos (Vigo). 


\section{Introdução}

Este artigo aborda a relação entre a fotografia e a emigração galega à América, reparando no seu papel na manutenção dos laços familiares e comunitários na comunidade galega. Para tal, serão analisados os trabalhos de vários fotógrafos populares do século passado, cujos arquivos foram recuperados estudados e valorizados pelo Centro de Estudos Fotográficos de Vigo (Galiza) nas últimas décadas através de trabalhos de campo que incluem entrevistas pessoais com os próprios fotógrafos, os familiares e alguns dos fotografados. Estudo que deu lugar a un importante número de exposições e livros monográficos. Prioriza-se a análise historiográfica, estética e das condições materiais da fotografia popular, em particular no meio rural. Como não se pode obviar o carácter dramático que a emigração teve, inclui-se um apartado dedicado à reportagem da despedida dos emigrantes realizada por Manuel Ferrol, para o seu estudo, no seu momento, contamos com os testemunhos do fotógrafo, do organizador da viagem e do protagonista da foto mais relevante.

A fotografia histórica galega tem um carácter singular e há duas características particulares da sociedade galega que têm nela grande influência: a emigração para a América e a disseminação da população.

Não é possível tratar nenhum aspeto da história contemporânea da Galiza sem ter presente o que significou a emigração. É rara a família que não teve vários familiares que emigraram para América, e a altíssima percentagem de galegos na emigração do Estado 
espanhol determinou que na América Latina os espanhóis fossem chamados de galegos. A emigração possibilitou, economicamente, a realização de fotografias e, por outro lado, dotou-a de sentido.

A emigração supunha a separação de famílias, o que determinou a realização de um grande número de fotomontagens para reunir a família separada pelo Atlântico. Desde a América, enviavam um retrato para o combinar com outro tirado aqui, mediante uma fotomontagem, como o encarregado por Rosa Gómez de Samieira, a partir de uma foto do seu marido tirada no estúdio Bartolomé Benicasa de Buenos Aires por volta de 1905 e outra dela realizada por Zagala em Pontevedra. As mais abundantes são de casais, mas também há de outros membros da família, como o caso de Josefa Insua de Sardiñeiro que a mandou fazer por ter saudades do seu irmão Casto, a quem se sentia muito unida ${ }^{1}$. As diferentes perspetivas e, às vezes, as datas diferentes das fotos utilizadas eram eliminadas perante um olhar atento. A procura que existia determinou que surgissem laboratórios especializados neste tipo de montagens, que frequentemente as iluminavam e podiam até adicionar alguma peça de joalharia. Este tipo de montagem também se realizava para conseguir uma foto de família quando algum dos membros já tinha falecido, ou quando, como era costume acontecer, não existia foto do casamento, pois a não existência da foto fazia com que parecesse que o vínculo não estava totalmente formalizado. Em todos os casos, a fotografia atua como um elemento de coesão da família. Lembro que quando mostrei alguma destas fotos a Joan Fontcuberta, ficou muito surpreendido, e posteriormente escreveu "[...] sustancialmente es cierta: auténticos eran los protagonistas, auténtica era la familia,

1 Informações obtidas em entrevistas do autor com familiares: Sara Rosales e Alberto Castro. 
auténticos los lazos entre unos y otros; de la fotografía solo eran falsas las circunstancias" (FONTCUBERTA, 1997, p. 128).

\section{Os fotógrafos populares e a emigração}

Ainda que a emigração tenha afetado toda a geografia galega, o fez de uma forma mais destacada na Galiza rural, pelo que é preciso lembrar o espalhar da população que caracteriza a Galiza, que ainda hoje possui 31.112 núcleos populacionais ${ }^{2}$, e que até os anos 90 representavam metade dos centros populacionais do Estado espanhol (NAVAZA, 1992). Em 1900, nove em cada dez pessoas viviam no mundo rural, em pequenos núcleos. Nos dois primeiros terços do século XX, que é o que abordaremos neste artigo, a sociedade galega é maioritariamente rural, situação bem diferente da atual. (BARREIRO FERNÁNDEZ, 1984) Por isso focar-nos-emos na pegada que deixou a emigração nos arquivos dos fotógrafos do mundo rural, que não possuíam galerias semelhantes às das cidades, como podiam ser as de Jaime Pacheco em Vigo, de José Pacheco em Ourense, de Ángel Blanco na Corunha, de Ksado em Santiago, de Bernardino González em Ferrol, de Constantino Rodríguez em Lugo, apenas para dar um exemplo de cada cidade, já que em cada uma delas existiam vários importantes. Nas vilas também existiam estúdios fotográficos, ainda que de menor representatividade que os das cidades importantes, e estes fotógrafos tinham por hábito deslocar-se por toda a sua comarca.

As instalações dos fotógrafos do mundo rural estavam

2 Instituto Galego de Estadística: http://bit.ly/2NkcepD 
frequentemente limitadas a um quarto onde tinham o laboratório e, por vezes, outro onde podiam fotografar, ainda que, escassamente, fotografassem no interior, dado que o seu controlo da iluminação artificial era muito precário. Fotografavam na horta, na porta da casa ou em diferentes lugares aos quais se deslocavam, iam pelas feiras e pelos concelhos limítrofes.

Para simular retratos de estúdio utilizam uma teia, uma colcha ou um pano de fundo comprado geralmente em segunda mão, e costumavam colocar no chão uma teia ou um tapete para tapar a terra. Esta singeleza de meios contrasta com a solenidade da pose. $\mathrm{O}$ ato de fotografar constituía um ato singular, muito pouco usual, e por isso posam com a solenidade que tal ato requer. Como tem revelado magistralmente o pintor galego Carlos Maside (1951), estas austeras fotografias populares caracterizam-se pelo estaticismo, hieratismo, verticalidade, frontalidade e simetria, acompanhados pela seriedade da expressão e o olhar direto para a câmara, que chega a provocar a confrontação direta com o espetador. Estas características da fotografia popular dão-lhe um claro caráter realista não isento de dramatismo, onde a subjetividade do fotógrafo parece não existir. Estes fotógrafos, como todos os profissionais do momento, limitamse a cumprir as encomendas que recebem sem qualquer pretensão. Mas é preciso lembrar que outros fotógrafos, inspirados neste tipo de fotografias, tornam estas características em recursos para a criação de uma obra de enorme interesse muito reconhecida no âmbito da arte. Podemos falar em August Sander na mesma década dos anos vinte, de Walker Evans na década de trinta, Richard Avedon em finais do século ou Rineke Dijkstra atualmente, para citar apenas alguns nomes. Neles, também, a subjetividade do fotógrafo parece não 
existir, a sua poderosa autoria baseia-se na não presença explícita. É o que se costuma denominar estilo documental, que Oliver Lugon (2001) tem estudado com grande rigor.

Os estúdios das cidades, onde o trabalho acostuma ser realizado por uma equipa de pessoas, contam com diferentes adereços como, por exemplo, carros pequenos, cavalos de cartão, poltronas, bancos e diversos panos de fundo para adaptar a cena ao tipo de fotografia de que se tratasse. Deles saem fotografias em que não existe hieratismo, as poses não são rígidas, mas descontraídas, simulando naturalidade e mesmo movimento. Desaparecem a frontalidade e o olhar direto para a câmara, mas pelo contrário insinuam-se sorrisos e olhares complacentes. O trabalho nestes estúdios permite iluminações mais sofisticadas, que chegam por vezes a imitar os retratos das atrizes que reproduzem as revistas do momento.

Foto 1 - Retrato de galeria, José Pacheco. Ourense, c. 1910.

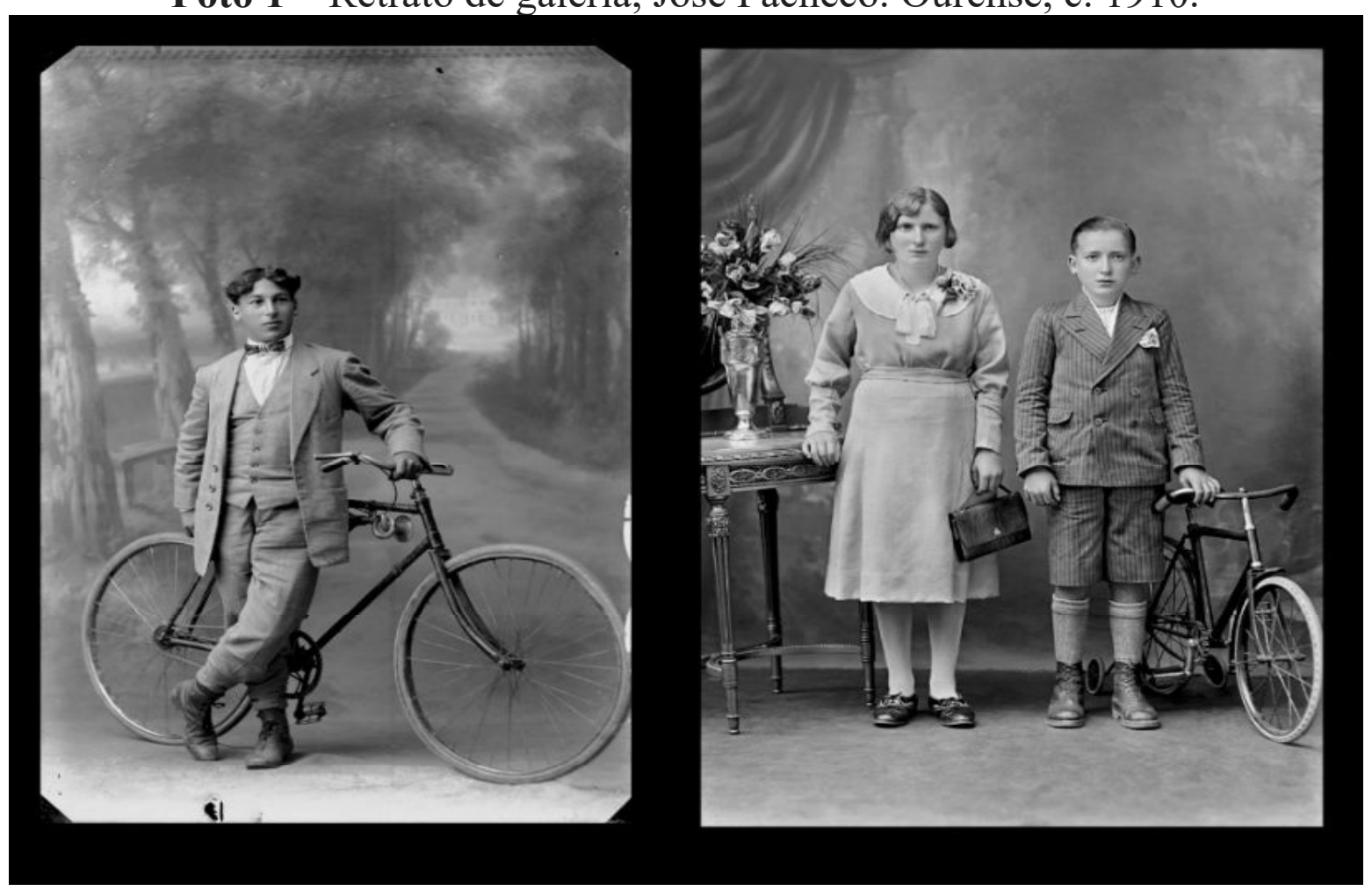

Fonte: Sendón e Suárez Canal (2010, p. 25). 
Porém, não seria adequado pensar que esta última é, em exclusivo, a estética dos estúdios urbanos enquanto que a anteriormente descrita corresponde à dos fotógrafos populares do mundo rural. Se observamos com atenção ambos os tipos de arquivos, comprovamos imediatamente como nos dos mais importantes estúdios urbanos também existem fotografias que obedecem às características da fotografia popular e nos arquivos dos fotógrafos rurais existem, numa proporção menor, fotografias que respondem às segundas características. Quando reparamos nas mãos e na maneira de vestir, percebemos que as pessoas posam de forma diferente em função do grupo social a que pertencem, e o papel do fotógrafo também é muito diferente em função da classe social do retratado. Perante a burguesia, ainda que dirija a cena, não parece ter a mesma autoridade, ou pelo menos o retratado não se sente intimidado da mesma maneira. O retrato é um luto, como dizia Richard Avedon, e nele obviamente influem as relações de classe. Podemos vê-lo claramente numa fotografia de Caamaño tirada em Fisterra, na qual umas raparigas posam com uma atitude descontraída, pose muito pouco frequente na sua fotografia (SENDÓN; SUÁREZ CANAL, 2010, p. 69); ou nas fotografias do arquivo Pacheco na cidade de Ourense (Foto 1), para citar apenas dois exemplos. Esta diferença pode perceber-se mesmo em fotografias de identidade da segunda metade do século $\mathrm{XX}$, o empregado do banco fotografado por Virxilio Vieitez não olha para a câmara como os outros. 
Foto 2 - Retrato, Ramón Caamaño. Muxía, c. 1930.

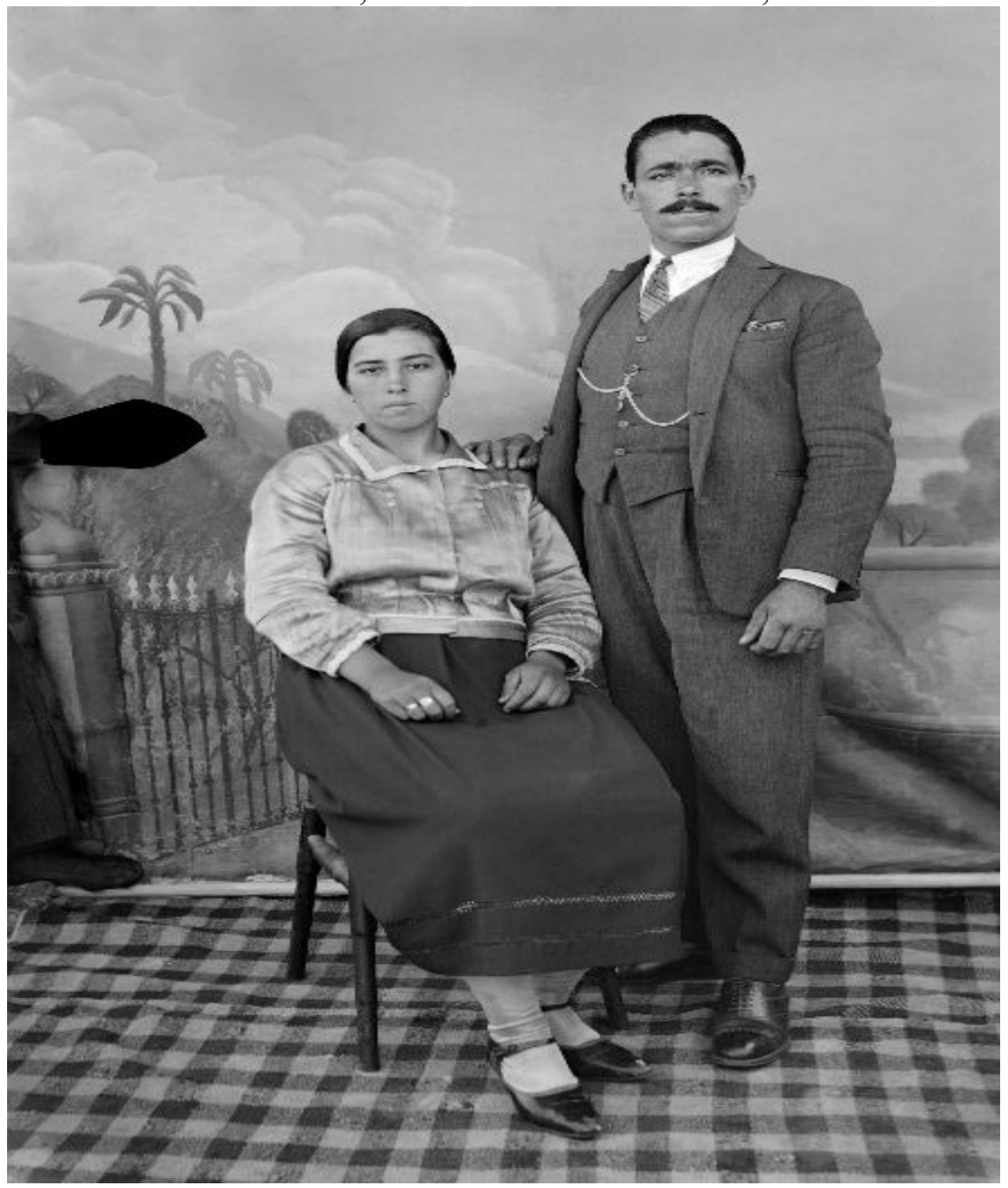

Fonte: Sendón e Suárez Canal (2010, p. 116).

Um exemplo de fotógrafo popular interessante é o de Ramón Caamaño, que começa a fotografar em Muxía, na Costa da Morte, em finais dos anos vinte do século passado, que nessa altura era um núcleo de população muito pequeno e muito isolado, a diferença do concelho é que tinha mais população do que na atualidade. Mas não limita o seu trabalho a Muxía, fotografa em toda a comarca, nos concelhos de Corcubión, Cee, Camariñas e Vimianzo, visitando as diferentes feiras, encontrando-se em algumas com Vidal de Laxe, 
outro fotógrafo de referência da Costa da Morte. Após terminado o trabalho de fotógrafo nessas localidades, aproveitava para projetar cinema, com um projetor Pathe Baby que havia comprado em 1927, provavelmente com dinheiro enviado pelo seu pai desde Cuba, convertendo armazéns, mercados do peixe, forjas... em salas de cinema.

Ao contrário de outros muitos arquivos que se perderam totalmente, conservou grande parte do seu, apesar de que também vendeu placas a Ubrique com a finalidade de ser eliminada a emulsão para ser empregue nas bilheteiras.

Graças ao seu pai ser emigrante em Cuba, livrou-se de ser marinheiro ou emigrante como os seus vizinhos, e pôde estar três anos a estudar na Escola de Artes e Ofícios de Santiago de Compostela e aprender o ofício no estúdio Ksado.

Caamaño fotografava na horta da sua casa, baixo um pequeno telhadinho, tapando o chão de terra com um tapete, empregando primeiro teias como pano de fundo, e depois um comprado ao fotógrafo Romero de Corcubión, mas também não faltaram as colchas. As suas imagens respondem totalmente às características descritas por Maside, e nelas é frequente encontrar retratos de mulheres sozinhas, e de mulheres com crianças, mas nas quais não aparece nenhum homem, presumivelmente na emigração. Também há fotografias nas quais o homem ostenta um relógio com corrente de ouro para, assim, tornar visível o triunfo na emigração, ou um emigrante retornado posando ao volante do seu Hispano Suízo com toda a família.

A forma de se relacionar com a morte nas culturas agrícolas e marinheiras era muito diferente da que existia no mundo urbano, 
assumia-se com muita mais naturalidade(GONDAR PORTOSONAY, 1987), o que implicou, como pudemos verificar por meio de vários arquivos $^{3}$, que os fotógrafos populares retratassem frequentemente pessoas mortas no seu caixão. Estas fotografias são muito diferentes das fotografias jornalísticas em que aparece a morte, não são fotografias do "outro". Caamaño fotografa no caixão da sua filha pequena morta, e do seu pai depois de ter regressado de Cuba.

Um caso muito particular é o de José Domínguez, conhecido como O Lucas, nascido em Chaín (Gondomar), que em criança viaja para o Uruguai, e que durante a sua vida realiza quase 20 viagens entre a Galiza e o Uruguai, até ao seu regresso definitivo em 1933. Em Montevideo monta, com S. Peragallo, o estúdio J. Domínguez y S. Peragallo, na rua Cerro núm. 21, depois denominada Bartolomé Mitre, frequentado por galegos, especialmente os advindos do Val Miñor, para serem fotografados. Segundo a família, também esteve estabelecido em Buenos Aires, mas não temos prova disto. Ao mesmo tempo atua como correio, trazendo para a Galiza fotos dos emigrantes da sua comarca, tiradas em Montevideo e vice-versa, levando para Montevideo as das famílias que tinha retratado em Chavín. Mas não apenas retratos, também fez fotografias da romaria de Morgadáns para as levar posteriormente até à Asociación Amigos de Morgadáns como prova de que o dinheiro que tinha sido enviado para a sua organização cumprira o seu objetivo. Nas suas viagens não só transportava fotografias, também recolhia procurações para poder vender heranças, facto com o qual fez fortuna.

As fotografias tiradas em Montevideo eram as tradicionais

3 Principalmente os de Caamaño (SENDÓN; SUÁREZ CANAL, 2002, p. 8487, 2010, p. 65) e Vieitez (SENDÓN; SUÁREZ CANAL, 1998, p. 97- 105). 
de um estúdio de cidade, dispunha de diferentes panos de fundo e mobília para encenar as fotos, nas quais as pessoas posam de forma muito teatral simulando espontaneidade, absorvidos pela cena que representavam não olham para a câmara. Nada a ver com o hieratismo e o olhar direto para a câmara que caracteriza as fotos tiradas na aldeia de Chaín, durante a segunda e terceira década do século XX. Estas correspondem às características da fotografia popular anteriormente descritas. Em Chaín não tinha estúdio e fotografa nas ruas de terra da aldeia, e nas imagens percebe-se claramente o suporte colocado para pendurar o pano de fundo, sem faltar o habitual vaso e a cadeira com uma planta, em pleno acorde com a natureza vegetal em pano de fundo. Em muitas, vê-se claramente o chão de terra, mas em algumas está tapado com palha para simular um tapete, ou com uma teia branca que não cobre todo o chão para retratar uma menina de primeira comunhão vestida de branco. 
Foto 3 - Retrato, José Domínguez. Chaín (Gondomar), c. 1910-1940.

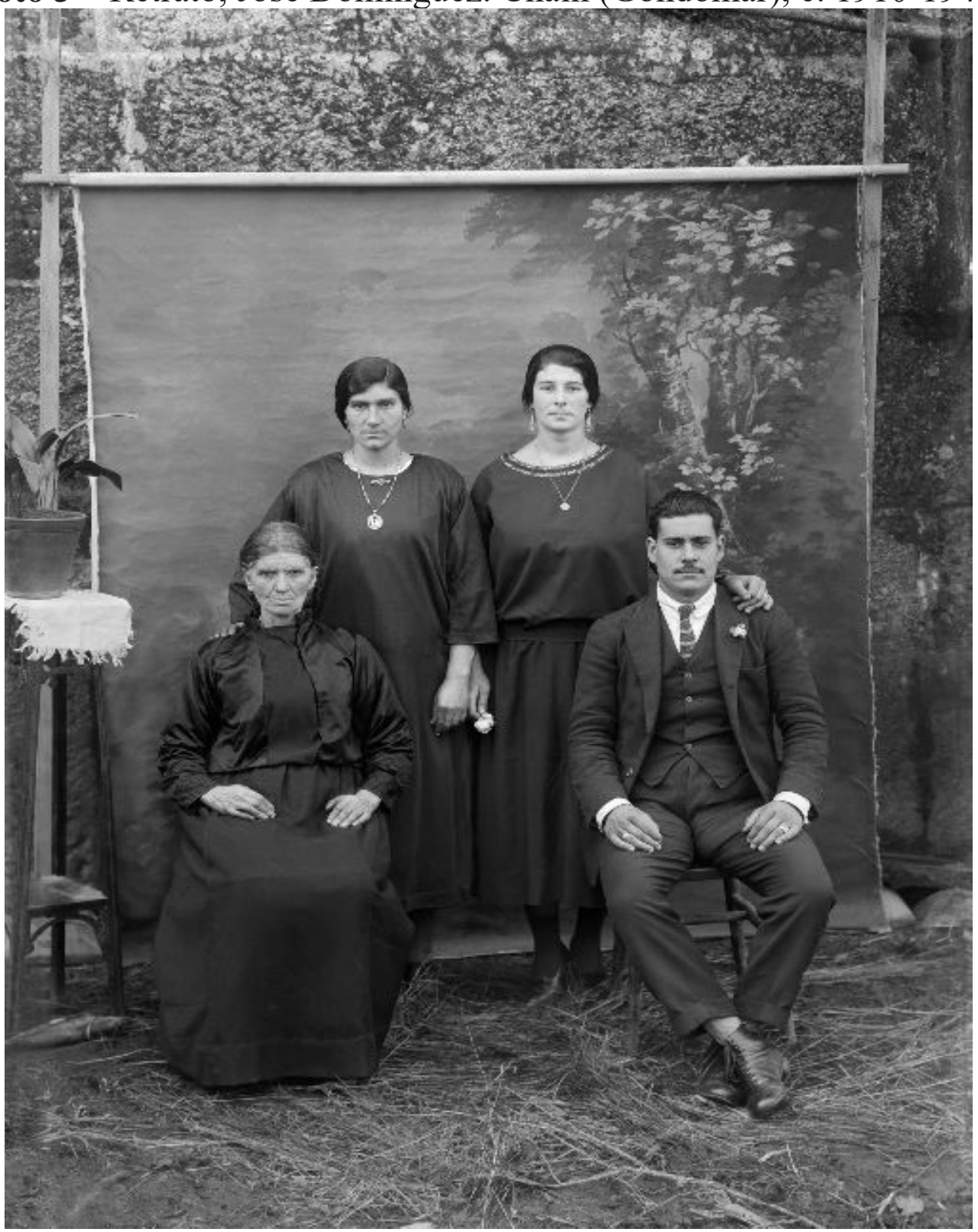

Fonte: Sendón e Suárez Canal (2010, p. 130).

A presença de plantas a enfeitar a cena, ou de flores nas mãos, é uma constante em todos os fotógrafos populares. Neste sentido são especialmente interessantes as realizadas por Pedro Brey entre 1917 e 1940, no vale do Ulla e no Concelho da Estrada, nas quais não estão apenas presentes as flores. Numa delas, além das flores aparece uma menina carregando cachos de uvas e uma planta de milho com espigas, um bonito canto à fecundidade da terra. Nelas 
também pode se ver o suporte do pano de fundo sobre um chão de terra. Como vemos, é habitual a presença destes suportes, mostrando o contexto onde se tira a foto. Inicialmente, poderia pensar-se que depois, ao ampliar, seria reenquadrado, para que estes elementos não se vissem, como no caso de uma placa de Caamaño, na qual eliminou uma mão que sustentava o pano de fundo, mas em algumas esse corte faria com que alguns elementos ficassem de fora, como o vaso que Domínguez coloca para uma foto de família, ou noutras, pessoas, como acontece na fotografia de uma família de 13 filhos tirada por Vidal em 1930, para a qual precisa colocar duas colchas como pano de fundo, e ainda assim não cobre toda a família. Se a reenquadrasse, ficariam fora a mãe e os dois filhos mais pequenos. Isto leva-nos a pensar que estes panos de fundo acabam por se tornar em elementos retóricos, como os vasos após perderem a sua função de imobilizar os indivíduos.

Quando os fotógrafos com galeria se deslocam às aldeias, fazem-no com critérios semelhantes aos populares. A título de exemplo, podemos citar as tiradas em Avión pelos irmãos Chao, com estúdio em Ribadavia, feitas sempre no mesmo recanto em que o papel do pano de fundo é feito por uma casa abandonada, e nas mãos das raparigas, que posam hieraticamente numa foto frontal, sem que faltem as flores.

\section{Manuel Ferrol - A despedida de emigrantes}

No dia 27 de outubro de 1957, Manuel Ferrol fotografa no porto da Coruña a despedida de emigrantes galegos com destino à Argentina no barco Juan de Garay. A viagem era organizada pela 
Comissão Católica de Emigração com o objetivo de reunir famílias, levando familiares de pessoas que haviam emigrado previamente. Este trabalho mostra, como nenhum outro, o drama que pressupôs a emigração galega para a América, e coloca Ferrol num lugar de honra dentro da fotografia galega.

Para contextualizar este trabalho dever-se-á ter presente a dimensão da emigração galega para a América em geral a que fazíamos referência, e de uma forma particular a desta década em que emigram mais de 200000 pessoas, a imensa maioria para a América.

As fotografias são tiradas com uma câmara Rolleiflex, que graças ao seu tipo de visor permitia que se pudesse transportar debaixo da gabardina sem ser notada. Assim, veremos como a maioria das personagens não têm consciência de que estão a ser fotografadas, sendo maiormente as crianças as que se apercebem da presença da câmara, provavelmente devido tanto à sua estatura, como à distração a respeito da cena que está a acontecer. Dadas as difíceis condições de luz dos lugares cobertos onde as fotos iam ser realizadas, hipersensibilizava previamente a película com mercúrio ${ }^{4}$.

Ferrol fotografa as pessoas de frente sem prestar qualquer tipo de atenção aos efeitos formais que tanto preocupavam os amadores. Pelo contrário, em muitas delas percebem-se características que normalmente eram consideradas por eles como defeitos de principiante. Assim, são frequentes as imagens movidas ou desfocadas, horizontais e verticais caídas, as altas luzes com halo que invadem os sujeitos fotografados, imagens cinzentas... Peculiaridades que contribuem para reforçar a veracidade e a 4 Conversa mantida com Manuel Ferrol en junho de 1995. 
expressividade do momento e do sofrimento experienciado pelos seus protagonistas. Como exemplo poderia citar-se a fotografia " $A$ confissão antes de ir para o outro mundo" feita por Ferrol o 27 de outubro de 1957, onde um padre sentado numa banqueta está a confessar um jovem de joelhos num dos espaços cobertos da estação marítima, imagem totalmente cinzenta e com as verticais caídas, efeitos que contribuíam para mostrar a pobreza do lugar, reforçando o ambiente dramático da cena, ao mesmo tempo que sugere um futuro incerto. Nas imagens das mulheres durante a missa de despedida, a desfocagem, os corpos movidos, as luzes queimadas e a halação contribuem para a identificação das personagens com a iconografia religiosa. Noutras, as massas totalmente desfocadas do primeiro plano ajudam a destacar uma personagem reforçando a sua expressividade.

É preciso destacar também a escolha do momento em que são tiradas, captando grande expressividade nos rostos. A tristeza, o temor, a dor, a incerteza e o cansaço surgem claramente refletidos. Quando analisamos algumas das imagens e reparamos atentamente nos rostos das diferentes pessoas, percebemos a pluralidade de expressões que aparecem numa só imagem. Como exemplo poderíamos colocar a foto onde mistura o olhar frontal surpreendido de uma criança a brincar com um brinquedo de madeira, que contrasta com a expressão de cansaço de uma senhora que boceja, e o olhar entre curiosidade e desconfiança de dois homens.

Os enquadramentos são realizados de forma espontânea e intuitiva, e contrastam com as imagens formais e muito cuidadas tecnicamente dos afeiçoados desse período, como, por exemplo, a muito cuidada composição formal realizada por Raniero Fernández 
ao transatlântico Antilles, em 1955 no porto de Vigo, onde entravam os barcos que saíram da Corunha. Ferrol considera que "se fala de composição quando a foto não te diz nada. É como quando uma pessoa fala de algo que não te interessa, pensas noutra coisa" ${ }^{5}$. É preciso destacar que, depois de uma rigorosa reflexão, se encenassem fotografias para sintetizar o que significou a emigração, não seria fácil que alcançassem a força visual destas imagens.

De forma particular é preciso citar a imagem na qual, no momento em que as sereias do barco começam a tocar para anunciar a partida, o pai começa a chorar por simpatia com o choro do filho (foto 4). O protagonista da fotografia, Ángel Calo Marcote, conhecido como Jurjo pelos seus vizinhos de Fisterra, despedia-se com o seu filho, a sua mãe, o seu irmão e a sua irmã que caminhavam para encontrar o seu pai. Ángel Calo não voltou a ver a sua mãe, tal como pressentia nesse momento. A imagem é tirada no momento decisivo, um instante onde o sofrimento fica patente de uma forma difícil de superar; num segundo plano ligeiramente desfocado, aparece à direita um padre, elemento no qual, seguramente, o fotógrafo não reparou ao tirar a foto, mas que na leitura pode sugerir o papel que a igreja estava a ter. Esta fotografia acabou por se tornar no ícone da emigração galega, como é a de Robert Capa da Guerra Civil espanhola. Foi publicada, fragmentada, pela primeira vez em 1958 por Luis Seoane na revista Galicia Emigrante 6 que dirigia em Buenos Aires, e juntamente com outras seis imagens foi incluída no livro Galicia hoxe (FERNÁNDEZ; BROCOS, 1966).

5 Conversa mantida com Manuel Ferrol en junho de 1995.

6 Reproduzida fragmentada no número 35, correspondente a VI-VII de 1958 da revista Galicia Emigrante, Buenos Aires, p. 25. 
Foto 4 - Fotografia da despedida de emigrantes, Manuel Ferrol. A Coruña, 1957.

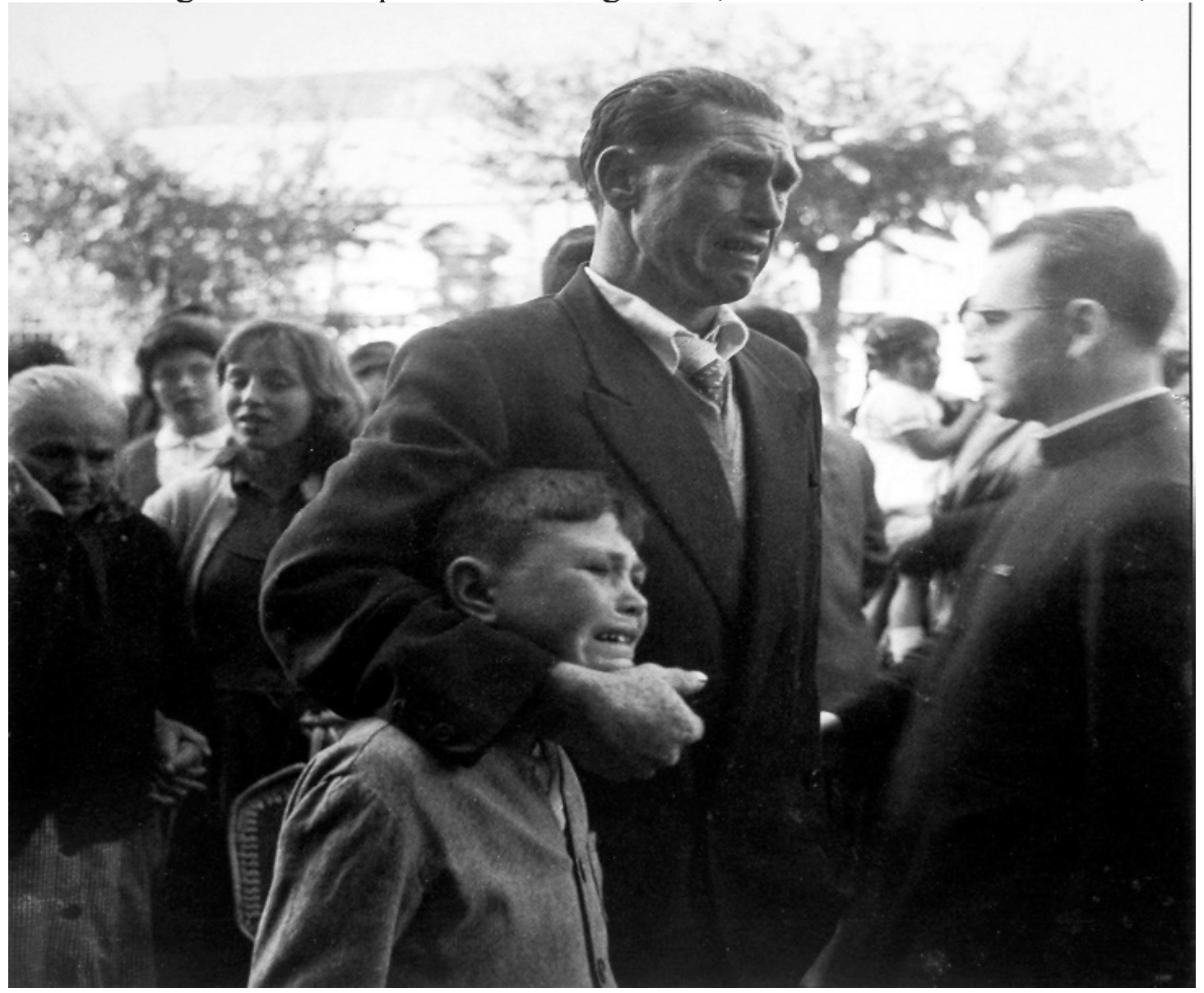

Fonte: Ferrol (1986).

No ano 1986, iniciamos o percurso editorial do Centro de Estudos Fotográficos com a edição do livro Emigración de Manuel Ferrol, que recolhe uma vintena de imagens desta série. Posteriormente, em 1998, dentro da VII Fotobienal de Vigo mostramos a série completa, incluindo o álbum que no momento criou a Comissão Católica de Emigração. Além disso, a fotografia de Jurjo e do seu filho foi reproduzida constantemente em livros, posters, jornais, revistas, capas de discos... No filme Sempre Xonxa, desta época com a emigração como tema de fundo, Chano Piñeiro constrói as cenas da despedida dos emigrantes a partir destas fotografias, incluindo nelas, a título de homenagem, o próprio 
Manuel Ferrol a fotografar.

No ano de 1986, vinte e nove anos depois de ter tirado a fotografia de Jurjo com o seu filho, reencontra-se pela primeira vez com o protagonista da imagem. E instantes depois de lhe ser apresentado, na inauguração da exposição em Fisterra, ouvi ele dizer: "Há muitos anos que me pergunto o que pensaria de mim por lhe ter tirado esta fotografia". Na realidade, estava a expor com palavras simples o problema que se formulavam nessa altura alguns documentalistas de outros países, questionando que o fotógrafo tivesse direito a fotografar as vítimas de uma situação dolorosa e injusta, por se recusar a converter os que sofrem, pertencentes normalmente a um outro grupo social, "os outros", em objetos de contemplação ${ }^{7}$.

A habilidade de Manuel Ferrol para, através destas imagens, mostrar o sofrimento que pressupôs a emigração fica claramente provado, podendo provavelmente ser considerado este trabalho como a reportagem mais expressivamente dramática da fotografia histórica galega, transcendendo o seu interesse pela fotografia galega.

Alberto Martí (2010) também fotografa a despedida de emigrantes no porto da Corunha, em finais da década de cinquenta e inícios da de sessenta, realizando imagens emblemáticas como Os adeuses (1957), em que os familiares se despedem desde o cais levantando os seus lenços brancos, ou a de duas crianças com baú e mala que perderam o barco e tiveram de o ir apanhar a Vigo. Um trabalho também de grande interesse (MARTÍ, 2010).

Estas fotografias podem ser consideradas também, em certa medida, como a despedida da emigração americana, pois se até esse 7 Sobre o vitimismo, e a fotografia do "outro" pode ver-se: (GIBBS, 1990; SEKULA, 1984; SENDÓN, 1991, p. 227; SENDÓN; SUÁREZ CANAL, 1990, p. 29-68). 
momento a emigração era sinónimo de emigração para América, na década de sessenta os emigrantes dirigem-se maioritariamente para a Europa (GARCÍA DOMÍNGUEZ, 2010, p. 22-23).

\section{As fotos da emigração entram nas coleções de arte. Virxilio vieitez.}

Virxilio Vieitez, depois de ter aprendido o ofício na Catalunha, começa a fotografar em 1955 em Soutelo de Montes, num momento em que três em cada quatro galegos vivem no mundo rural. $\mathrm{O}$ seu território de trabalho foi mais amplo do que o dos fotógrafos do primeiro terço do século $\mathrm{XX}$, dado que conta primeiro com uma moto e depois com um carro para se poder deslocar até Cerdedo, Barro na província de Pontevedra e Avión, Beariz, na de Ourense, fotografando habitualmente no exterior, exceto nas festas de casamento e nos velórios. Dispõe de um pequeno quarto na casa para retratar, mas praticamente não o usa, nem domina a luz artificial. Trabalha com grande escassez de meios, lava as fotos e carretos na fonte do lugar, não tem fotómetro, e não costuma fazer diferentes fotografias de uma mesma cena. Apesar disso, os seus negativos são de uma qualidade excelente, sobretudo os realizados com a Rollei que compra no ano de 1957.

As características de hieratismo, frontalidade, simetria, olhar sério para a câmara, a solenidade do ato fotográfico, próprias dos fotógrafos populares, são as suas, mas as suas fotografias transcendem as dos fotógrafos populares. Para além do valor documental, antropológico ou sociológico, possuem um extraordinário interesse 
de um ponto de vista estético.

O tradicional papel do pano de fundo faz que o cumpram fundos naturais vegetais das hortas, complementados com umas couves em primeiro plano e flores nas mãos das mulheres; ou as estradas, conseguindo um grande impacto visual pela sensação de espaço baleiro que geravam. As encenações são tão vivas, como inauditas, nelas controla até os mais mínimos pormenores. Não há nada que seja acidental. A título de exemplo, podemos lembrar a foto de três mulheres pousando numa estrada, onde se colocou um vaso com uma frondosa planta de cada lado. As mãos das dos lados pousam sobre os ombros da do meio, mãe de uma e sogra da outra, que simbolizam a entrada na família de uma delas, que tinha casado no dia anterior. Apesar desta cuidada cenografia, onde controla mesmo como devem colocar os pés, a imagem não é sofisticada.

Foto 5 - Retrato de mulheres, Virxilio Vieitez. Barro de Arén, c.1958-60.

Foto 6 - Retrato de Dorotea de Cara, Virxilio Vieitez. Soutelo de Montes, c. 1960-61.
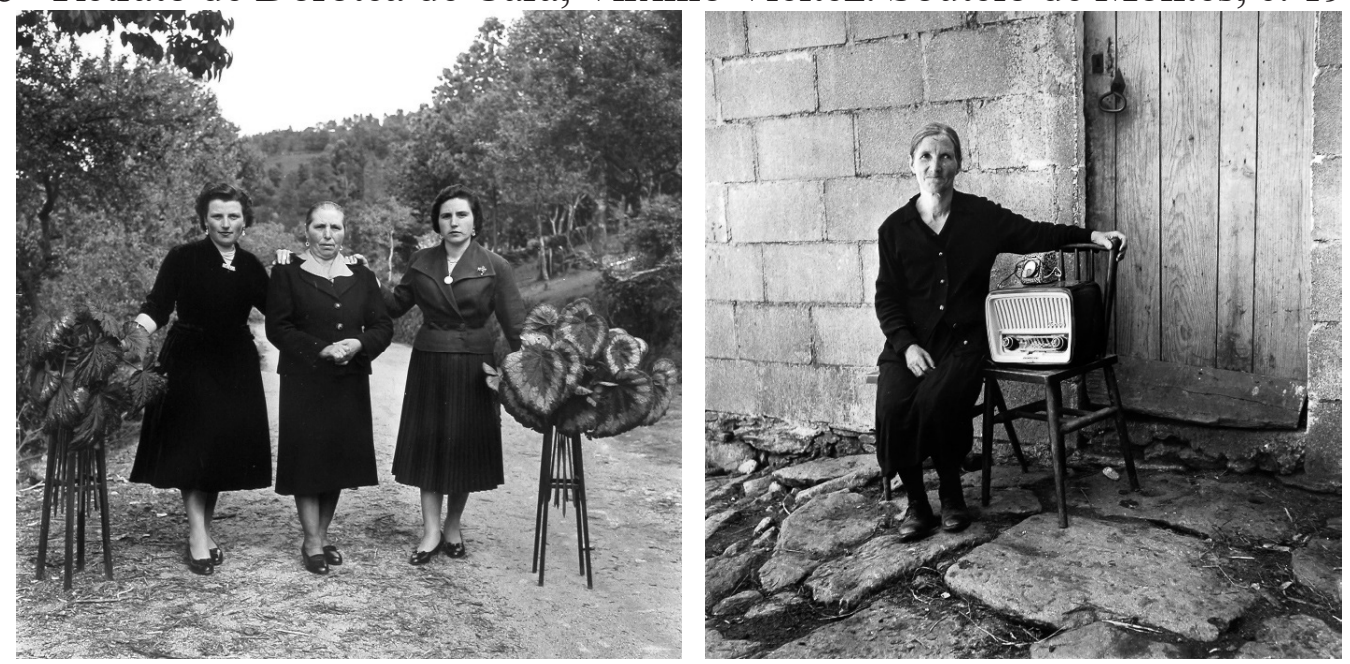

Fonte: Sendón e Suárez Canal (1998, p. 47, 87).

É preciso reparar também naquelas em que o papel do pano de fundo corresponde aos carros que traziam os emigrantes nos 
meses em que vinham de férias, os chamados haigas (carros grandes que pretendiam demonstrar o sucesso económico do emigrante retornado), diante dos quais posam pessoas e não são os proprietários. O contraste que se criava entre estes luxuosos carros e os caminhos de terra, quando não lodaçais, onde estavam estacionados, acaba por ser uma metáfora inconsciente da oportunidade perdida por não investir o dinheiro da emigração em projetos que gerassem desenvolvimento.

$\mathrm{O}$ ato fotográfico era um ato solene e, neste caso, chama a atenção sobre como relaciona a situação extraordinária que determina a foto com a vida quotidiana da sociedade labrega. Assim, vemos uma menina da primeira comunhão, ou senhoras vestidas para um casamento, entre couves; uma rapariga vestida de festa agarra com a mesma mão a corda da cabra e a mala, que provavelmente só usará esse dia durante todo o ano; um espigueiro por trás de um flamante haiga... Esta insólita convivência não é de todo grotesca, mas sim muito rica em significados. Não há a menor intenção de ridicularizar, tão frequente hoje nas fotos do mundo rural galego, e também não pintoresquismo. Virxilio não retrata estereótipos, "personagens típicas", não fotografa o "outro", mas pessoas próximas, retratadas com grande dignidade apesar de que havia penúrias. Esta dignidade é uma característica muito relevante das suas fotografias.

A consideração que se tem pelos animais domésticos na sociedade agrícola é magnificamente retratada nas suas imagens, tanto em imagens cheias de ternura, como a do rapaz, que posteriormente emigra para a Venezuela, pegando ao colo um gato como quem pega num bebé, imagem que não é produto do acaso, pois é exatamente repetida com a mãe do rapaz. Noutras, os animais estão ao pé dos donos a olhar fixamente para a câmara com uma pose similar à das 
pessoas.

A relação das fotografias de Virxilio com a América é muito forte, muitas das pessoas que retratou emigraram para a Argentina, o Brasil, o México, o Panamá, os Estados Unidos, e em particular para a Venezuela que, neste momento, ao contrário das décadas anteriores, era um destino muito frequente. Também aparece, em muito menor medida, a relação com a emigração para a Europa que começa em finais da década de cinquenta. Uma das três mulheres da foto anteriormente comentada emigra para França poucos dias após ter sido tirada a foto. Em outros muitos casos porque tinham sido realizadas expressamente para serem enviadas lá. Dorotea de Cará posa na rua com um rádio para enviar a foto ao filho e que assim comprove que o dinheiro que lhe enviara tinha sido empregue para o fim com que o tinha enviado. O jeito como que agarra a cadeira, o facto de que o rádio estar colocado como se fosse uma pessoa, torna-a num retrato da ausência do filho, mais do que da presença do rádio (foto 5 , direito).

Eram frequentes também as fotos de crianças encarregues pelos avós com que viviam, com o objetivo de as enviar aos pais para que comprovassem que estavam bem cuidadas, nas quais podem aparecer brinquedos, como um avião ou um cavalo de cartão, que tinham vindo da América. A relação também se estabelece mediante a roupa. Elena posa sorridente, uma exceção nas suas imagens, após um primeiro plano de couves e, no fundo, $O$ Chalé, a casa mais elegante de Soutelo, com roupas confecionadas com teia que lhe enviaram da América, provavelmente para a foto ser enviada para a América.

Percorreu a Terra de Montes realizando um grande número 
de fotos tipo passe e de passaporte, das quais algumas transcendem totalmente a sua função: são imagens vivas, em que o retratado nos devolve o olhar, autênticos retratos. Na fotografia de identificação "tudo está presente sem se tornar verdadeiramente visível" (FRIZOT, 1985, p. 7). Contudo, muitas das imagens realizadas por Virxilio para esta finalidade são, como diria Frizot: "portadoras de uma revelação que não se conformava com o parecido" (FRIZOT, 1985, p. 7). Para estas fotografias usa pano de fundo, um pano branco cravado com pinos, por vezes roto, que independentemente do caráter anedótico ou documental, contribui para dar uma grande força visual à imagem.

Quando, em 1997, vi um cartaz com a foto de Dorotea de Cará, surpreendeu-me tanto que imediatamente me desloquei a Soutelo para ver a exposição que anunciava. Na mostra, organizada pela sua filha Keta, ao pé de algumas imagens anedóticas de interesse local, havia outras sumamente interessantes, muito diferentes de toda a fotografia histórica que tinha visto, que pediam um estudo sério do arquivo. Durante um ano estudei-o com Xosé Luis Suárez Canal e, com a colaboração de Keta, focámo-nos no período de 1955-1965, por considerar que era o mais interessante, de uma forma particular cabe destacar o interesse das realizadas entre 1958 e 1960 com a câmara Rollei. Este estudo deu lugar, em 1998, a uma exposição de mais de uma centena de imagens, no âmbito da VIII Fotobienal de Vigo da qual éramos curadores, e a um livro na coleção Álbum do Centro de Estudos Fotográficos (SENDÓN; SUÁREZ CANAL, 1998) que dirigíamos.

Como tínhamos consciência de que o interesse do arquivo transcendia a Galiza, trabalhámos numa estratégia para o divulgar 
fora, sem considerar pertinente levá-lo, num primeiro momento, até uma cidade do Estado espanhol, dados os prejuízos que existem com a Galiza poderia não ser valorizado como considerávamos que merecia. Pensamos que Christian Caujolle, que dirigia a galeria da agência $V u$ que tinha sido inaugurada nesse momento, podia ser um bom legitimador. Convidámo-lo para fazer uma conferência na Fotobienal, para que assim visse a exposição, e quando a viu iniciou a segunda exposição da galeria, e as fotos de Virxilio são expostas em Paris vinte dias depois de se fechar a mostra em Vigo. Teve uma extraordinária receção, como também a teve aqui. O Le Monde (DANGEN, 1999) dedicou-lhe uma página e o Libération (LANÇON, 1999), duas. Estes artigos tiveram repercussão imediata no diário El País. As fotos de Virxilio entraram não apenas em coleções de fotografia, mas também em coleções de arte contemporânea como a do Centro Arte Reina Sofia de Madrid, ou na da Fondation Cartier pour l'Art Contemporain de Paris.

À medida que passam os anos sessenta, a sociedade vai mudando: a água corrente chega a Soutelo em 1964; no Changüi, onde se celebravam os casamentos, a forma tradicional de baile agarrado vê-se acompanhada do twist, chega a câmara Polaroid pela mão de algum emigrante... Estas mudanças refletem-se na forma de entender o ato fotográfico, as do baile solto são um bom exemplo disso. Assim, vemos imagens onde agora o hieratismo dá lugar a uma atitude distendida, aparece o movimento e o olhar sério e direto torna-se em sorrisos e expressões festivas. Desaparece a autoridade do fotógrafo, e em muitas das imagens não há já aquela cuidada e insólita construção, estando presente o acidental. Trata-se de valiosos documentos, mas carecem da magia das imagens anteriores, 
obviamente por elas não teria passado a história. Contudo, é preciso indicar que neste período também se realizam algumas imagens de grande interesse com formulações parecidas com as dos anos anteriores.

Em finais da década de sessenta começa a empregar a cor, que nas décadas seguintes passará a ser usada quase em exclusivo. A natureza tende a ser substituída pelos interiores. A luz natural pelo flash. As couves e animais domésticos por presentes de pelúcia, de bazar ou por cartas. O haiga, pelo aparador cheio de garrafas de licor, nas abundantes imagens de noivas no interior. Além disso, muitas delas não inspiram a mesma dignidade que as do primeiro período e sim mais tristeza, e não têm o mesmo interesse.

Muitas das imagens de Virxilio lembram-nos as de Sander, Evans, Avedon, que ele desconhecia, semelhanças que vimos escritas no Le Monde: "a obra de Virxilio Vieitez poderia ser de uma importância em nada inferior à de Walker Evans, por exemplo, ou August Sander" (DAGEN, 1999). Mas Virxilio era muito diferente: fotografa sem outra pretensão que resolver uma encomenda "para mim, todas as imagens são iguais, pagaram-me o mesmo por elas". Não existia, pois, a intenção de estabelecer uma relação entre as imagens através de uma escolma (uma proposta) como exige a obra de arte na modernidade, como aconteceu no caso dos anteriormente citados. Portanto, não pode ser considerado como um artista tal como se entende na modernidade, nem pensou pretender sê-lo.

Virxilio criou um arquivo de dezenas de milhares de negativos, e um arquivo é um espaço de acumulação excessivamente amplo para configurar, por si próprio, uma obra de arte (KRAUSS, $8 \quad$ Conversa mantida com Virxilio Vieitez em 1998. 
2002). Contudo, não podemos concluir dizendo que o trabalho de Atget, Seydou Keita ou de Virxilio Vieitez sejam arquivos apenas e não obras de um artista. Não podemos considerar iguais todos os arquivos. Independentemente do imenso valor documental que um arquivo pode ter para uma comunidade, há alguns que transcendem esse valor documental. Assim, o arquivo de Atget, composto por 30000 placas realizadas no primeiro terço do século $\mathrm{XX}$, ampliou consideravelmente o horizonte fotográfico e teve uma grande influência sobre muitos fotógrafos posteriores que foram reconhecidos como artistas. Um caso análogo ao de Virxilio é o de Seydou Keita, que trabalhou no Mali a tirar retratos por encomenda na mesma altura que Virxilio e, apesar da distância geográfica, as suas obras têm certas semelhanças. O rádio de Keita tem um papel diferente do de Virxilio, mas o mesmo que os seus haigas.

Se aceitarmos que um autor é definido pela especificidade da sua obra, não podemos ser insensíveis à "especificidade" de determinados arquivos, que como o de Virxilio obviamente a têm. De alguma forma é preciso falar numa "autoria de arquivo", diferente da autoria da modernidade. Esta autoria de arquivo seria baseada na singularidade que globalmente têm as imagens. Apesar de se tratar de uma acumulação de imagens, sem outra estruturação que aquela que exige a sua comercialização, são produtos de uma conceção fotográfica intuitiva que define claramente uma forma particular de construir as imagens que transcendem o grande interesse documental que possam ter. Desde esta ótica valorizamos o arquivo de Atget, e considero que também devemos fazer o mesmo com o de Virxilio (SENDÓN, 2013).

Depois de surgir nos meios expositivos a obra de Virxilio, 
houve quem pensasse que era fácil encontrar outros fotógrafos semelhantes. Tal não aconteceu, de facto é um caso único dentro da fotografia do Estado espanhol. Isto não significa que a história da fotografia esteja fechada e que não possa ser submetida a revisão, como tem acontecido recentemente na América com o arquivo de Vivian Maier.

O que é certo é que quando se edita ou se expõe a obra de Virxilio, ou de um arquivo em geral, o papel que cumpre o artista é assumido pelo curador. O critério que seguimos, X. L. Suárez e eu, em 1998 é muito diferente dos que se seguiram na exposição que foi realizada em 2003 em Vigo e que, transformada, viajou posteriormente para Madrid. Tanto no que faz referência ao critério de escolma (diferença entre as relevantes e anedóticas), como ao número (excessivo), às dimensões (sobre dimensão), aos emoldurados (molduras às cores na de Vigo) e ainda a colocação em espaço (o bosque de colunas da de Madrid). Definitivamente, como tenho reiterado noutras ocasiões, o arquivo de Virxilio é um diamante em bruto, pelo que é preciso dar muita atenção a como se talha, ou corremos o risco de o estragar.

Mas a valorização será uma outra se consideramos que "a função da arte é a de instaurar em cada época modelos de visão (e de comportamento)" (ROGER, 2007, p. 106) reivindicando o caráter artístico da obra de fotógrafos topográficos do XIX: “[...] são artistas, já que o nosso olhar depende ainda, em grande parte, das "paisagens históricas" que criaram há mais de um século" (ROGER, 2007, p. 106). 


\section{Consideraçoes finais}

A viagem pelas obras dos fotógrafos do século passado, combinando as obras de fotógrafos populares com outras de fotógrafos das cidades, dá-nos uma visão ampla e complexa da importância da fotografia para o conhecimento da emigração galega. A análise da fotografia popular, pela mão de fotógrafos como Ramón Caamaño, José Domínguez, Pedro Brey ou Virxilio Vieitez, permitiunos conhecer as características da estética da fotografia popular que prevalecem na maioria dos retratos destinados a comunicar-se com a família ausente. Paralelamente, a recuperação e análise de obras documentales como a de Manuel Ferrol mostram-nos o drama da emigração do ponto de vista de um espectador externo. Uma arqueologia destas obras, como a realizada ao longo do nosso trabalho no Centro de Estudos Fotográficos de Vigo, é imensamente valiosa porque nos permite explorar as diferentes visualidades e estéticas que a emigração galega deixou, bem como os valores estéticos dos mesmo que, como no caso de Vieitez, tenham saído desses arquivos para penetrar nas coleções de arte.

\section{Referências}

BARREIRO FENÁNDEZ, Xosé Ramón. Historia política: siglos XIX-XX. A Coruña: Ediciones Gamma, 1984. (Historia contemporánea de Galicia, t. 4.)

CAGIAO VILA, Pilar. Instantes para alembranza. In: MARTI, Alberto. Os adeuses. Fotografías. Santiago de Compostela: Xunta de Galicia, 2010. 
DAGEN, Philippe. Soixante chef-d'oeuvre de Virxilio Vieitez. Le Monde, París, 13 jan. 1999.

FERNÁNDEZ, Santiago; BROCOS, Maximino. Galicia hoy. Buenos Aires: Ruedo Ibérico, 1966.

FERROL, Manuel. Emigración. Vigo: Centro de Estudos Fotográficos, 1986.

FONTCUBERTA, Joan. EI beso de Judas. Barcelona: Gustavo Gili, 1997.

FRIZOT, Michel. Idem ou le visage de l'autre. In: IDENTITÉS. De Disderi au Photomaton. París: Centre National de la Photograpnie, 1985.

GARCÍA DOMÍNGUEZ, María Teresa. As políticas migratorias no franquismo. In: MARTI, Alberto. Os adeuses. Fotografías. Santiago de Compostela: Xunta de Galicia, 2010.

GIBBS, Michael. Critical realism. Perspektief Magazine, Rotterdam, n. 39, p. $38-58,1990$.

GONDAR PORTOSONAY, Marcial. A morte. Santiago de Compostela: Cadernos do Museo do Pobo Galego, 1987.

KRAUSS, Rosalind. Los espacios discursivos de la fotografía. In: KRAUSS, Rosalind E. Lo fotográfico: por una teoría de los desplazamientos. Barcelona: Gustavo Gili, 2002.

LANÇON, Philippe. Vieitez. Regards sur la Galice. Liberation, París, 25 jan. 1999.

LUCAS, Antonio; VIGANÒ, Enrica; ROSENBLUM, Naomi; VILLARES, Ramón; ORSI, Lucia. Virxilio Vieitez. Madrid: Fundación MARCO: Fundación Telefónica, 2011. 
LUGON, Oliver. Estilo documental. Salamanca: Universidad de Salamanca, 2001.

MARTÍ, Alberto. Os adeuses. Santiago: Consello da Cultura Galega: CGAI, 2010.

MASIDE, Carlos. En torno a la fotografía popular. Vigo: Galaxia, 1951. (Colección Grial, n. 2).

NAVAZA, Gonzalo. Limiar. In: CABEZA QUILES, Fernando. Topónimos de Galicia: a súa orixe e o seu significado. Vigo: Edicións Xerais de Galicia, 1992.

ROGER, Alain. Breve tratado del paisaje. Madrid: Biblioteca Nueva, 2007.

SEKULA, Allan. Dismantling Modernism, Reinventing Documentary (notes on the politics of representation). In: PHOTOGRAPHY against the grain: essays and photoworks 1973-1983. Halifax: Press of the Nova Scotia College of Art and Design, 1984.

SENDÓN, Manuel. Diamante Virxilio. Faro da Cultura, Vigo, 18 abr. 2013. Disponível em: http://bit.ly/2M6oV6C. Acesso em: 10 nov. 2020.

SENDÓN, Manuel. Imaxes na penumbra. A fotografía afeccionada en Galicia (1950-1965). Vigo: Edicións Xerais, 1998.

SENDÓN, Manuel. O documentalismo social na fotografia. A Trabe de Ouro, Madrid, España, ano 2, t. 2, 1991. Disponível em: http://encurtador.com.br/kyOQ1. Acesso em: 10 nov. 2020.

SENDÓN, Manuel. Virxilio Vieitez, un desprazamento de espazo discursivo. 2013. A Trabe de Ouro, Madrid, España, n. 96, p. 7586, 2013. Disponível em: http://bit.ly/35V1ILI. Acesso em: 10 nov. 2020 . 
SENDÓN, Manuel; SUÁREZ CANAL, Xosé Luis. Documentalismo social contemporáneo. In: FOTOBIENAL DE VIGO, 4., 1990, Vigo. Catálogo [...]. Vigo: Centro de Estudos Fotográficos, 1990. p. 29-68. 